\title{
QUE GEOMETRIA MODERNA PARA AS ESCOLAS DO BRASIL E DE PORTUGAL?
}

\author{
Which modern geometry for Brazilian \\ and Portuguese's schools?
}

Maria Célia Leme da Silva

Doutora em Educação pela PUC/SP - GHEMAT - UNIBAN. São Paulo, SP - Brasil, email: mcelialeme@gmail.com

\begin{abstract}
Resumo
O presente artigo apresenta resultados parciais de uma pesquisa maior cujo objetivo é investigar como foi a trajetória do ensino de geometria no Brasil e em Portugal, durante o MMM, e realizar um estudo histórico-comparativo. São discutidas as primeiras produções didáticas para o ensino de Matemática na abordagem moderna em relação ao ensino de geometria, nas séries finais do ensino secundário. No Brasil, analisamos um livro de Benedito Castrucci e em Portugal, o material elaborado por Sebastião e Silva. Consideramos que compreender o ensino de geometria durante o MMM no Brasil, tendo a possibilidade de dialogar com uma investigação similar em Portugal, parece-nos muito interessante: as opções e entendimentos brasileiros ganham significados novos ao estabelecermos a comparação com a realidade portuguesa.
\end{abstract}

Palavras-chave: Ensino de geometria; Movimento da Matemática Moderna; História da educação matemática.

Rev. Diálogo Educ., Curitiba, v. 8, n. 25, p. 689-699, set./dez. 2008 


\section{Abstract}

In this paper, we present partial results from a major research, which aims investigating Brazilian and Portuguese's Geometry teaching trajectory, during Modern Mathematics Movement (MMM), and realising a historic-comparative study. We discuss the first didactical productions, in a modern approach, for Geometry teaching in High School's last years (16-17 year-old). We have analysed Brazilian textbook from Benedito Castrucci and Portuguese production from Sebastião e Silva. We consider that comprehending Geometry teaching during Brazilian MMM, if compared to a Portuguese similar investigation, can be very interesting: Brazilian options and understandings acquire new meanings, if we establish comparisons with Portuguese reality.

Keywords: Geometry teaching; Modern mathematics movement; Mathematics education history.

\section{INTRODUÇÃO}

Movimento da Matemática Moderna (MMM) foi como se tornou conhecido o movimento internacional de reformulação no ensino da matemática escolar. Final da década de 50, início dos anos 60, comissões, grupos de estudos, seminários, congressos, nacionais e internacionais sobre a educação matemática, discutem as novas propostas para o ensino da matemática. As mudanças propostas pelo Movimento defendiam a unificação dos diferentes campos da matemática, aproximando o ensino realizado na educação básica àquele desenvolvido na Universidade, o que corresponde à linguagem e à estrutura empregada pelos matemáticos da época.

Neste artigo, apresentamos os resultados parciais de uma pesquisa ${ }^{1}$ que tem como objetivo investigar como foi a trajetória do ensino de geometria no Brasil e em Portugal, durante o MMM, e realizar um estudo histórico-comparativo. A idéia de desenvolver um estudo histórico comparativo é um desafio, na medida que a produção histórica carrega uma tradição de ser produzida nacionalmente. Os estudos históricos comparativos colocam a questão do trânsito entre países,

\footnotetext{
A pesquisa intitulada A trajetória da geometria escolar no Brasil e em Portugal e o Movimento da Matemática Moderna está inserida no Projeto A Matemática Moderna nas escolas do Brasil e de Portugal: estudos históricos comparativos de Cooperação Internacional Capes-Grices, entre Brasil e Portugal.
}

Rev. Diálogo Educ., Curitiba, v. 8, n. 25, p. 689-699, set./dez. 2008 
entre culturas, permitindo que determinados problemas sejam compreendidos para além do que poderiam ser os seus determinantes regionais (VALENTE, 2006). Apostamos que buscar comparar culturas distintas por meio de uma temática comum, na nossa pesquisa, o Movimento da Matemática Moderna, nos possibilita conhecer melhor o Movimento em si e suas apropriações em cada realidade.

\section{ENSINO DE GEOMETRIA NO BRASIL}

O Movimento da Matemática Moderna, no Brasil, ganha força com a criação do GEEM - Grupo de Estudos do Ensino da Matemática, em 1961, na cidade de São Paulo. Este grupo tem um papel preponderante na introdução e divulgação do Movimento no Brasil. Participaram do Grupo professores universitários, professores dos ensinos secundário e primário, autores de livros didáticos, todos com o objetivo de incentivar, coordenar, divulgar e atualizar o ensino da matemática.

Destacamos para esta análise inicial o professor Benedito Castrucci, ${ }^{2}$ que participou ativamente do GEEM, ministrou cursos para professores e produziu material didático. É possível dizer que foi o responsável pelo ensino de geometria no Grupo. Castrucci também foi autor de livros didáticos para o ensino secundário desde a década de 50, tendo publicações anteriores e posteriores ao MMM.

Nossa análise inicial sobre como Benedito Castrucci tratou a geometria nas propostas de modernização do ensino da matemática foi feita considerando como fonte de pesquisa seus livros didáticos. ${ }^{3}$ Em 1968, Castrucci publica o livro didático Geometria curso moderno em substituição ao anterior Lições de Geometria elementar, destinado aos alunos do ensino secundário, ${ }^{4}$ cujo prefácio, anuncia as mudanças propostas no livro em decorrência do MMM.

Ao compararmos os dois livros de Castrucci, percebe-se a inclusão, na abordagem moderna, de dois capítulos iniciais: o primeiro, Noções de lógica e o segundo Elementos de teoria dos Conjuntos, antes do estudo da Geometria. É bastante evidente,

Benedito Castrucci (1909-1995). Bacharel em Ciências Jurídicas e Sociais em 1935, e licenciado em Ciências Matemáticas e Físicas, pela Universidade de São Paulo, em 1939. Em 1940, foi designado para o cargo de assistente de Geometria e, posteriormente, foi contratado para o cargo de assistente científico da Cadeira de Geometria Projetiva e Analítica. Em 1943, doutorouse pela Faculdade de Filosofia, Ciências e Letras da Universidade de São Paulo, em Ciências Matemáticas.

3 Uma primeira discussão acerca desse assunto encontra-se publicado em LEME DA SILVA, M. C.; OLIVEIRA, M. C. A. A geometria e o Movimento da Matemática Moderna no Brasil: cenas de um casamento conturbado. In: PROFMAT 2006. Actas do Profmat 2006. Associação de Professores de Matemática. Portugal, 2006.

4 Ensino secundário era destinado aos alunos de 15 a 17 anos de idade.

Rev. Diálogo Educ., Curitiba, v. 8, n. 25, p. 689-699, set./dez. 2008 
também, a nova linguagem empregada pelo autor. Os teoremas, antes enunciados e demonstrados em linguagem natural, na versão moderna da Geometria, incorpora a simbologia utilizada na teoria dos Conjuntos. Em outras palavras, pode-se dizer que a nova obra é a anterior revestida de uma nova linguagem, sem, entretanto, uma mudança de abordagem de proposta pedagógica. Castrucci comenta no Prefácio que:

Há um movimento para a substituição do conteúdo geométrico no curso colegial e, talvez, no ginasial, por uma algebrização da Geometria, tratando-a como um capítulo de Álgebra Linear. Acreditamos que esta inovação preconizada por grandes matemáticos não possa ser feita imediatamente, pois a nosso ver seria, no momento, um passo ousado. (CASTRUCCI, 1968, prefácio).

O posicionamento de Castrucci frente à incorporação das novas propostas para o ensino de geometria é de muita cautela. Por que será que o professor assume esta postura, sendo um dos professores do GEEM que esteve mais ligado as questões referentes ao ensino de geometria?

É o próprio Castrucci quem nos explica seu posicionamento, numa entrevista concedida à pesquisadora Elizabethe Búrigo, para sua dissertação de mestrado, intitulada Movimento da Matemática Moderna no Brasil: estudo da ação e do pensamento de educadores matemáticos nos anos 60, defendida em 1989. A pesquisadora nos cedeu a entrevista, na qual Castrucci, primeiro diz existirem duas possibilidades para a incorporação da geometria ao modelo das estruturas algébricas: uma vetorialmente e outra pelas transformações. E a seguir, expõe os problemas que, enquanto formador de professores, enfrentou com ambas:

No meio dessa idéia nós, então, resolvemos dar essa reciclagem (aos professores) [...] Então eu dei um curso de planos vetoriais. $\mathrm{E}$ os meus cursos todos tinham muito êxito, muitos alunos e professores e dessa vez eu fracassei. Quer dizer, os alunos não reagiram bem, acabaram não fazendo boas provas, porque nós tínhamos muita avaliação, não é, e eles não se saíram bem. Então eu disse, será que eu estou ficando mau professor? Eu não soube apanhar bem a coisa, mas daí tentei mais um outro curso em um outro lugar, também não funcionou...E aí nós tentamos ensinar... eu também dei um curso de geometria das transformações, por isometrias, [...], fracasso maior ainda. (CASTRUCCI, entrevista concedida à BURIGO, 1988).

Rev. Diálogo Educ., Curitiba, v. 8, n. 25, p. 689-699, set./dez. 2008 
Para fazer um contra ponto do posicionamento de Castrucci sobre o ensino de geometria, trazemos para análise uma discussão realizada na Primeira Conferência Inter-Americana sobre Educação Matemática, Bogotá, Colômbia, em dezembro de 1961. Nesse encontro, o professor Howard F. Fehr (1962), dos EUA, faz uma conferência com o título Reforma do Ensino da Geometria. Em sua fala, ele tece considerações sobre o desenvolvimento da Geometria como campo matemático e, em seguida, discute o ensino da geometria. Segundo ele, durante as primeiras décadas do século XX, o movimento dedicado a refinar a base axiomática da Geometria de Euclides surtiu pouco ou nenhum efeito sobre o ensino dessa matéria tanto no nível secundário quanto universitário. Essa situação de inércia mudou na década de $30 \mathrm{com}$ o renascimento do interesse pelos axiomas de Hilbert como base apropriada para um programa de instrução na escola secundária.

Fehr aponta duas tendências ao ensino da geometria a partir de então. A primeira, elaborada por G. D. Birkhoff, propunha uma modificação significativa dos axiomas de Euclides, seguindo a forma geral imposta por Hilbert, porém conseguindo uma grande economia ao fazer uso das propriedades do conjunto dos números reais: a de ordem e a de completividade. Com o patrocínio da National Science Foundation (NSF), os axiomas de Birkhoff, modificados por sua vez por Edwin C. Moise, foram usados na preparação de textos experimentais que eram utilizados em muitos colégios dos Estados Unidos. Ele ainda conclui que os atuais tratamentos reformulados da Geometria naquele país eram dirigidos essencialmente para a conservação da Geometria de Euclides, corrigidos seus defeitos por meio da introdução dos números reais.

A segunda tendência discutida por Fehr é o estudo da geometria na escola secundária, iniciado na Alemanha, onde se aplicavam, de forma bastante generalizada, alguns aspectos do Programa de Erlangen, de Klein, que propõe o desenvolvimento da Geometria por meio das transformações geométricas. O grupo de transformações (rotações, reflexões e translações) é utilizado para caracterizar a Geometria euclidiana, porém precedida de um sistema de axiomas que conservam a congruência de triângulos da Geometria de Euclides como fundamentais para o desenvolvimento posterior do estudo da Geometria.

Em síntese, concluímos que Castrucci, na obra Geometria curso moderno não segue nenhuma das duas tendências apontadas por Fehr. Os postulados permanecem os mesmos, ou seja, a medida não é acrescentada ao grupo de axiomas, como propõe Birkhoff. Também não são desenvolvidas as transformações geométricas, baseada em Klein. Castrucci, muito cauteloso, mantém-se com poucas alterações e julga ousado demais realizar as propostas preconizadas pelo MMM prematuramente.

Rev. Diálogo Educ., Curitiba, v. 8, n. 25, p. 689-699, set./dez. 2008 


\section{Ensino de geometria em Portugal}

O Movimento da Matemática Moderna, em Portugal, diferentemente do Brasil, não se difunde pela ação de um grupo de estudo. Em 1963, é nomeada uma Comissão de estudos para a modernização do ensino da Matemática, ${ }^{5}$ composta por quatro professores de matemática. Um desses professores, José Sebastião e Silva, ${ }^{6}$ ganha destaque por ser o designado para a elaboração de manuais didáticos a serem experimentados nas chamadas turmas pilotos para os alunos do $3^{\circ}$ ciclo liceal. ${ }^{7}$

Desta forma, a implementação da modernização do ensino de matemática, em Portugal, se inicia, em turmas piloto, para o final do ensino secundário, com a utilização de material didático elaborado por Sebastião e Silva, em três volumes. Descrevemos a seguir a síntese de uma primeira análise realizada no material elaborado por Sebastião e Silva. ${ }^{8}$

O ensino da geometria é desenvolvido, especificamente no volume 3. Percebe-se, nos dois primeiros volumes da proposta, que a geometria, quando é tratada, adquire um status de exemplo, não é ela o tema central, seus conceitos e relações são discutidos sempre num contexto maior, seja de funções, seja de estruturas algébricas. Os conceitos da geometria euclidiana plana e espacial são utilizados como ferramenta nos exercícios propostos, em geral, são elementos de conjuntos determinados que juntamente com operações definidas sobre tais elementos configuram estruturas algébricas especiais. Não há capítulo dedicado ao estudo da geometria, ela encontra-se subordinada aos outros conceitos.

No volume 3, o ensino de geometria é introduzido por meio do cálculo vetorial. Apresenta-se o conceito de vetor, soma de um ponto com um vetor, soma de dois vetores, geometricamente. A primeira transformação trabalhada é a translação,

Portaria do Ministério da Educação Nacional de 17 de julho de 1963. (AIRES, A. P. F. O conceito de derivada no ensino secundário em Portugal ao longo do século XX: uma abordagem histórica através dos planos curriculares e manuais escolares. 2006. 290 f. Tese (Doutorado no Departamento de Didáctica de La Matemática y Didáctica De Las Ciencias Experimentales). Universidade de Salamanca, Espanha, 2006.

6 SILVA, J. S. Compêndio de matemática. Lisboa: GEP, 1975. v. 3. (Curso complementar do ensino secundário). Licenciado em Ciências Matemáticas na Faculdade de Ciências de Lisboa em 1937. Em 1960 foi nomeado professor catedrático da Faculdade de Ciências de Lisboa, regendo disciplinas fundamentais de Análise Superior e História do Pensamento Matemático. As contribuições mais significativas de Sebastião e Silva se situaram no campo da Análise Funcional e, sobretudo, na teoria dos funcionais analíticos, na teoria das distribuições e no cálculo simbólico.

Alunos de 16 e 17 anos. Corresponde ao $2 .^{\circ}$ e $3 .^{\circ}$ colegial do atual Ensino Médio brasileiro.

8 O texto completo desse trabalho encontra-se em LEME DA SILVA, M. C. A geometria escolar em Portugal e no Brasil: primeiros estudos. MATOS, J. M.; VALENTE, W. R. (Org.). A matemática moderna nas escolas do Brasil e de Portugal: primeiros estudos. São Paulo: Vinci/CAPES, 2007. p. 81-103.

Rev. Diálogo Educ., Curitiba, v. 8, n. 25, p. 689-699, set./dez. 2008 
definida como uma aplicação. A seguir é definido produto de um número real por um vetor. Nesse item, com os conceitos anteriormente construídos, Sebastião e Silva apresenta a terna $(\vartheta,+,$.$) como um espaço vectorial sobre o corpo \mathbb{R}$, ou um espaço vectorial real, sendo $\vartheta$ o conjunto de todos os vectores do espaço, + a operação de soma de dois vetores e . o produto de um escalar por um vector. É nesse momento que o autor define as condições para que um conjunto $S$ de elementos quaisquer munido das operações + e . seja um espaço vectorial sobre um dado corpo K (SILVA, 1975, p. 44-45). Ainda no mesmo capítulo, apresenta a definição de homotetia, também como uma aplicação particular do espaço ; vetores colineares e coplanares, e finaliza com referências cartesianas em forma vetorial.

Há, ainda, um capítulo dedicado às transformações geométricas. São estudadas: transformações de semelhança e isometrias, rotações do plano e do espaço, reflexões, deslocamentos e isometrias negativas, sempre relacionadas com as estruturas algébricas. O fechamento desse estudo é feito pela definição de figuras iguais:

Diz-se que duas figuras F e G são geometricamente iguais, e escreve-se $F \cong G$, estes são positivamente isométricas no espaço, isto é, se existe pelo menos um deslocamento que aplica G sobre F. (SILVA, 1975, p. 94).

Logo depois, Sebastião e Silva comenta a noção intuitiva do conceito de igualdade de figuras com a definição anteriormente realizada. Ou seja, a igualdade entre duas figuras é assegurada pela existência de transformações geométricas que as sobreponham.

Como se vê, a noção de igualdade geométrica é-nos sugerida pela nossa experiência quotidiana com os corpos sólidos. Diz-se que um corpo é sólido (ou rígido), quando não é susceptível de mudar de forma nem de dimensões, mas apenas de posição (em relação a outro sólido). Essa mudança de posição em movimentos, que são compostos de uma infinidade contínua de deslocamentos, no decorrer do tempo. Deste modo, um sólido representa sempre figuras geométricas iguais nas suas diferentes posições - e dois sólidos serão iguais, se puderem ocupar exatamente o mesmo lugar no espaço, um após o outro (ao mesmo tempo é impossível, segundo o PRINCÍPIO DA IMPENETRABILIDADE DA MATÉRIA). (SILVA, 1975, p. 95).

Rev. Diálogo Educ., Curitiba, v. 8, n. 25, p. 689-699, set./dez. 2008 
A sequência dos temas desenvolvidos são: transformações afins, efeito das transformações afins sobre retas paralelas e sobre vetores, aplicações lineares, determinação de todas as possíveis afinidades entre dois planos ou do espaço, determinação de todas as possíveis semelhanças, isometrias e deslocamentos, entre dois planos ou do espaço e aplicações afins.

Pode-se dizer que a proposta apresentada por Sebastião e Silva para a modernização do ensino da matemática nas turmas-piloto em relação ao ensino de geometria, é a geometria das transformações geométricas e a geometria dos espaços vetoriais. Sebastião e Silva propõe para o ensino secundário temas tratados nas disciplinas de Geometria Analítica e de Álgebra Linear do ensino superior. Nota-se ainda que a álgebra predomina, é ela que estrutura o desenvolvimento do estudo, dos temas tratados, e assim, evidencia-se um processo de algebrização da geometria.

Da mesma forma que Castrucci, buscamos um contraponto da apropriação de Sebastião e Silva com discussões internacionais sobre o ensino de geometria. Em 1959, realiza-se o Seminário de Royaumont, na França. Segundo Guimarães (2006), essa reunião é certamente a realização mais emblemática de todo o movimento reformador de grande influência internacional, que recebeu o nome de Matemática Moderna. Respeitando o desenvolvimento da matemática pura da época e dele se aproximando, uma das conclusões apontadas no Seminário foi unificar os diferentes campos da Matemática, respeitando sua unidade. "Não é mais necessário que o curso de Álgebra seja isolado e paralelo aos cursos de Aritmética, de Geometria, de Trigonometria e de Análise" (OECE, 1961, p. 115).

Em relação especificamente ao ensino de geometria, um episódio marcante no Seminário de Royaumont, foi a fala de Jean Dieudonné, matemático do grupo Bourbaki, ' que, em sua Conferência, para sintetizar e exemplificar as idéias por ele defendidas na nova proposta de ensino, enuncia uma frase que se tornou emblemática: "Se eu quisesse resumir numa frase todo o programa que tenho em mente, fá-lo-ia com o slogan: Abaixo Euclides!" (OECE, 1961, p. 35).

Entretanto, Dieudonné, esclarece que tem profunda admiração pelos resultados encontrados pelos gregos na Matemática. Ressalta, porém, a necessidade de reorganização da geometria euclidiana após a metade do século 19, para reavaliar sua importância em relação às matemáticas modernas. Propõe dois princípios diretores na reformulação do ensino da matemática. O primeiro é desenvolver uma teoria matemática sob a forma axiomática, quando o aluno esteja familiarizado com as questões sobre as quais ela se aplica e tenha trabalhado um certo tempo sobre uma base experimental ou semi-experimental. O segundo princípio é manter uma honestidade rigorosa ao introduzir a dedução lógica nas questões matemáticas,

Esse grupo foi criado em 1934, exerceu forte influência sobre a produção Matemática durante várias décadas.

Rev. Diálogo Educ., Curitiba, v. 8, n. 25, p. 689-699, set./dez. 2008 
Que geometria moderna para as escolas do Brasil e de Portugal? 697

o que significa dizer, sem dissimular as lacunas ou os defeitos de raciocínio. Como exemplo, cita o ensino atual da geometria, que se inicia com as sequências de definições que não definem nada e de pseudodemonstrações que não resistem à análise lógica (OECE, 1961, p. 40).

Ainda em referência ao ensino da geometria, Dieudonné acrescenta: As minhas críticas visam, portanto, não à finalidade mas aos métodos do ensino da Geometria; afirmo sobretudo que seria muito melhor basear este ensino, não em noções e resultados artificiais que, na maior parte das aplicações não tem nenhuma utilidade, mas em noções fundamentais que dominam $\mathrm{e}$ esclarecem todas as questões onde a Geometria intervém. No momento em que, por exemplo, a noção de vector tem uma importância capital em toda a ciência moderna, a noção de triângulo é artificial e não tem praticamente nenhuma aplicação. (OECE, 1961, p. 47).

A tese defendida pelo matemático bourbakista é a de um ensino da geometria inteiramente baseado nos vetores e espaço vetorial com duas dimensões, com sugestões para uma extensão a três dimensões. É neste sentido que a abordagem euclidiana perde sua importância.

Desta forma, em relação às discussões sobre o ensino da geometria no Seminário de Royaumont, de 1959, a proposta de Sebastião e Silva assemelhase à abordagem defendida por Dieudonné, ou seja, de uma geometria baseada nos vetores e nos espaços vetoriais. Entretanto, a introdução dessa nova abordagem para o ensino da geometria não significa romper ou negar o estudo da geometria euclidiana. Muito pelo contrário, os alunos selecionados para realizar a experiência de modernização do ensino da matemática, nas turmas-piloto, eram os que tinham um bom desempenho na matemática. Isso significa que tais alunos haviam realizado, com bom aproveitamento, o $2^{\circ}$ ciclo do ensino liceal, que correspondia a um estudo completo da geometria euclidiana plana e espacial.

Em síntese, consideramos que Sebastião e Silva consegue, em sua proposta para o ensino de geometria para as turmas-piloto, traduzir de forma harmoniosa uma das conclusões do Seminário de Royaumont:

É indispensável que esses assuntos (geometria plana e espacial, álgebra e trigonometria) sejam ensinados no seu encadeamento lógico, mais profundo e com mais rigor [...] e um ensino tão precoce quanto possível das relações que unem a Geometria à Álgebra - particularmente a Álgebra linear e vetorial. (OECE, 1961, p. 128-129).

Rev. Diálogo Educ., Curitiba, v. 8, n. 25, p. 689-699, set./dez. 2008 


\section{CONSIDERAÇÕES FINAIS}

Ressaltamos, uma vez mais, que os resultados aqui apresentados são parciais e que a pesquisa encontra-se em desenvolvimento. Apontamos, entretanto, as comparações que até o momento julgamos oportunas, entre a visão de Benedito Castrucci e de Sebastião e Silva.

Identificamos um ponto de partida similar entre Sebastião e Silva e Castrucci, ou seja, a mudança do ensino da geometria, segundo dois caminhos, o dos espaços vetoriais e o das transformações geométricas. Entretanto, a materialização dessa concepção inicial é bastante diferenciada. Sebastião e Silva desenvolveu uma proposta única para o ensino da matemática, global e a geometria é inserida na proposta mais ampla, enquanto Castrucci realizou um curso específico sobre geometria. Sebastião e Silva selecionou, no início, professores e alunos para desenvolver a proposta; Castrucci ministrou cursos para professores de maneira geral, sem uma seleção prévia.

Outra semelhança entre os dois pontos de vista diz respeito aos cuidados na implementação de mudanças no ensino da matemática. Castrucci, talvez, tendo a dimensão do que significava realizar a algebrização da geometria no ensino secundário brasileiro, tenha tido receios em implementar uma proposta dessa natureza. Entretanto, é possível questionarmos se, em alguma medida, Sebastião e Silva também teve um posicionamento semelhante ao de Castrucci, porém com ações diferenciadas. Para viabilizar sua experiência, desenvolveu um material para ser utilizado em turmas piloto, turmas estas selecionados, com alunos e professores bem preparados, com os conhecimentos básicos da matemática tradicional e os lançou para a modernização do ensino da matemática.

Diante desses primeiros questionamentos apontados na presente análise, é possível notar a importância de considerar as diferentes apropriações de um Movimento, tendo em vista as diferenças culturais. Entretanto, compreender como o ensino de geometria foi tratado durante o MMM no Brasil, tendo a possibilidade de dialogar com uma investigação similar em Portugal, parece-nos muito interessante: as opções e entendimentos brasileiros ganham significados novos ao estabelecermos a comparação com a realidade portuguesa.

\section{REFERÊNCIAS}

AIRES, A. P. F. O conceito de derivada no ensino secundário em Portugal ao longo do século XX: uma abordagem histórica através dos planos curriculares e manuais escolares. 2006. $290 \mathrm{f}$. Tese (Doutorado no Departamento de Didáctica de La Matemática y Didáctica De Las Ciencias Experimentales) - Universidade de Salamanca, Salamanca, Espanha, 2006.

Rev. Diálogo Educ., Curitiba, v. 8, n. 25, p. 689-699, set./dez. 2008 
Que geometria moderna para as escolas do Brasil e de Portugal? 699

CASTRUCCI, B. Geometria curso moderno. São Paulo: Nobel, 1968. . Entrevista concedida à Elizabete. [S. 1.]: Zardo Búrigo, 1988.

FEHR, H. F. Reforma do ensino da geometria. In: FEHR, H. F. (Org.). Educacion matematica en las Americanas. Columbia: Teachers College Columbia University, 1962. p. 64-78.

GUIMARÃES, H. M. Por uma matemática nova nas escolas secundárias: perspectivas e orientações curriculares da Matemática Moderna. In: SEMINÁRIO TEMÁTICO - A MATEMÁTICA MODERNA NAS ESCOLAS DO BRASIL E EM PORTUGAL: ESTUDOS HISTÓRICOS COMPARATIVOS, 2., 2006, Lisboa. Anais... Lisboa, Grupo de Pesquisa de História da Educação Matemática no Brasil, 2006.

LEME DA SILVA, M. C.; OLIVEIRA, M. C. A. A geometria e o Movimento da Matemática Moderna no Brasil: cenas de um casamento conturbado. In: PROFMAT 2006. Actas do Profmat 2006. Associação de Professores de Matemática. Portugal, 2006.

LEME DA SILVA, M. C. A geometria escolar em Portugal e no Brasil: primeiros estudos. MATOS, J. M.; VALENTE, W. R. (Org.). A matemática moderna nas escolas do Brasil e de Portugal: primeiros estudos. São Paulo: Vinci/CAPES, 2007, p. 81-103.

ORGANIZAÇÃO EUROPEIA PARA A COOPERAÇÃO ECONÓMICA - OECE. Mathématiques nouvelles. Paris: OECE, 1961.

SILVA, J. S. Compêndio de matemática. Lisboa: GEP, 1975. v. 3. (Curso complementar do ensino secundário).

VALENTE, W. R. Estudar Portugal para entender o Brasil e vice-versa: algumas considerações sobre história comparativa em educação matemática. In: SEMINÁRIO TEMÁTICO - A MATEMÁTICA MODERNA NAS ESCOLAS DO BRASIL E EM PORTUGAL: ESTUDOS HISTÓRICOS COMPARATIVOS. 1., 2006, Lisboa. Anais... Lisboa, Grupo de Pesquisa de História da Educação Matemática no Brasil, 2006.

Recebido: 29/05/2008

Received: $05 / 29 / 2008$

Aprovado: $01 / 07 / 2008$

Approved: 07/01/2008

Rev. Diálogo Educ., Curitiba, v. 8, n. 25, p. 689-699, set./dez. 2008 